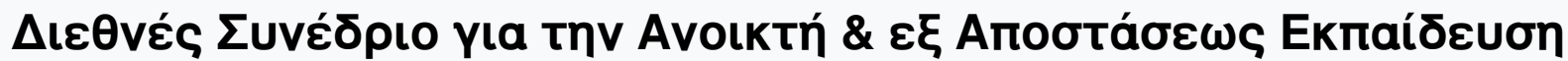

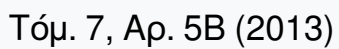

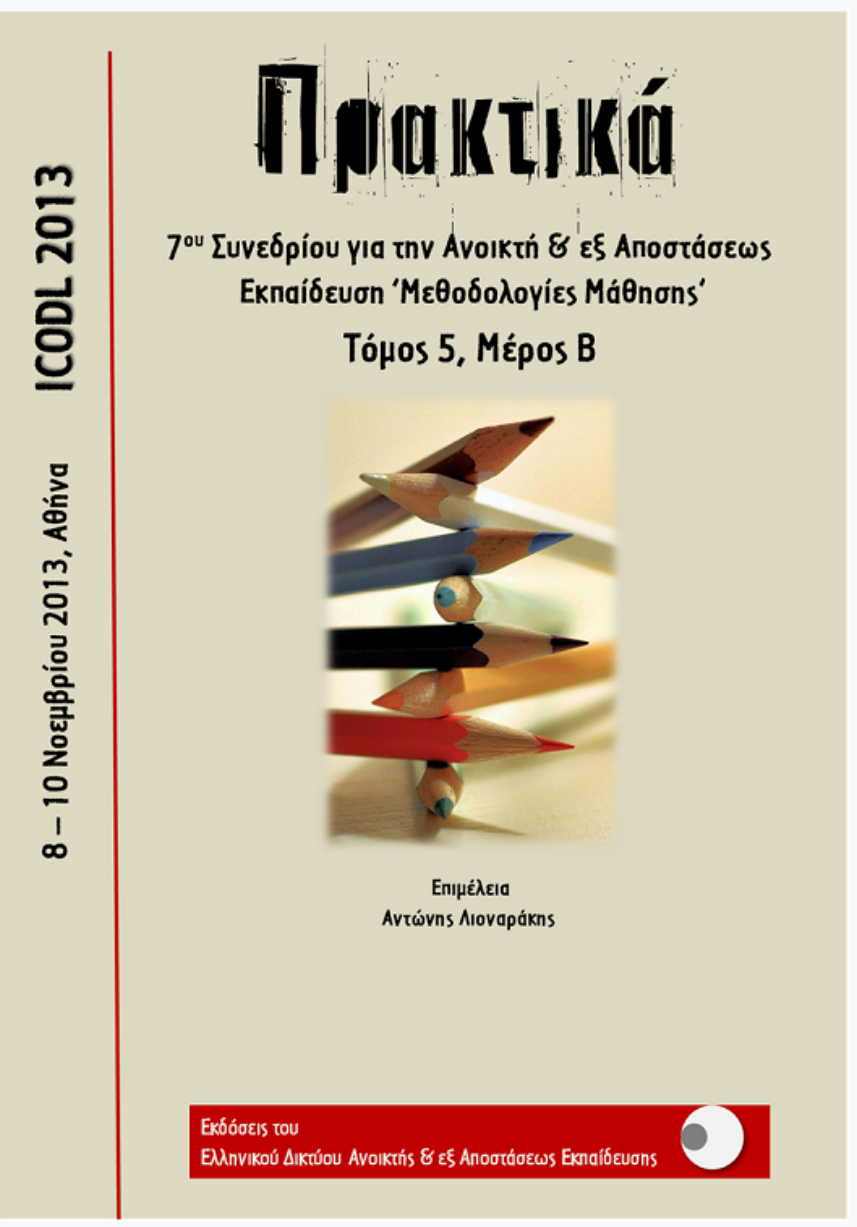

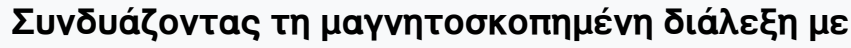

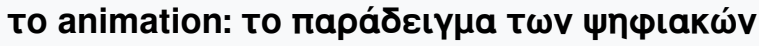
$\mu a \theta \eta \mu a ́ t \omega v$ tou MIO-ESCEDE

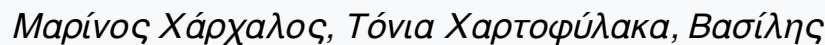

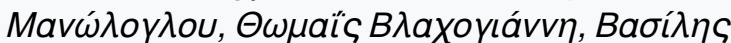

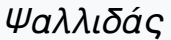

doi: $\underline{10.12681 / \text { icodl. } 569}$ 


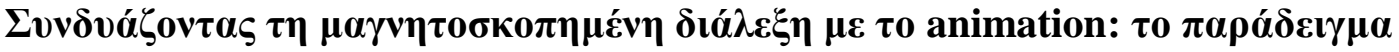

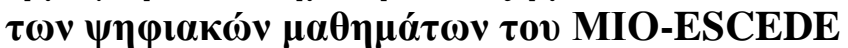

\section{Combining video lectures with animation: the example of MIO-ESCEDE e- learning courses}

\begin{tabular}{|c|c|c|c|}
\hline 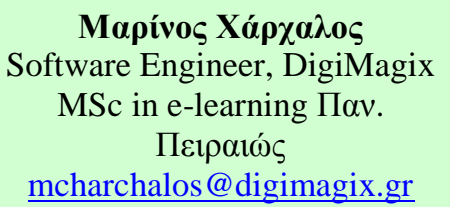 & \multicolumn{2}{|c|}{ 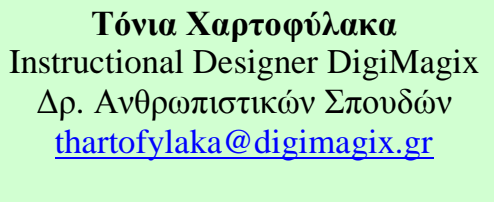 } & 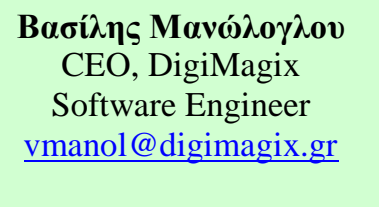 \\
\hline \multicolumn{2}{|c|}{ 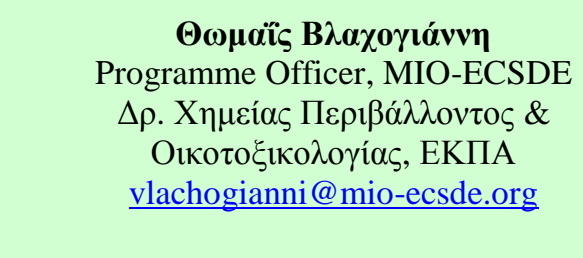 } & \multicolumn{2}{|c|}{ 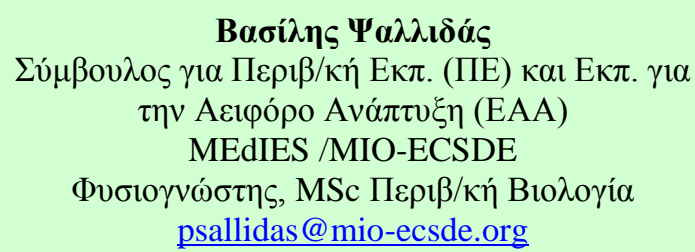 } \\
\hline
\end{tabular}

\begin{abstract}
The present paper illuminates the necessity to manage the different forms of educational material in order to create a complete educational package and presents the technological solution to achieve that scope. The paper consists of two parts. In the first part, we outline the special role of the distance learning educational material and the different forms that it may take. In the second part we take as an example the e-learning courses of MIO-ESCEDE in order to present the technological solution, with which we managed to combine two distinct forms of material in a single environment.
\end{abstract}

\section{Пврі́ $\eta \psi \eta$}

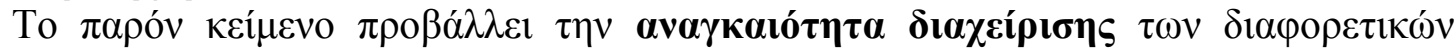

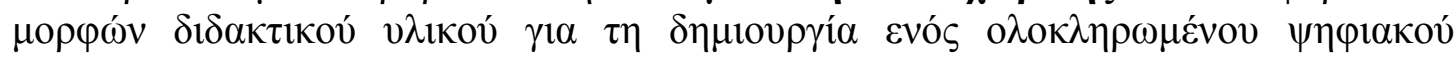

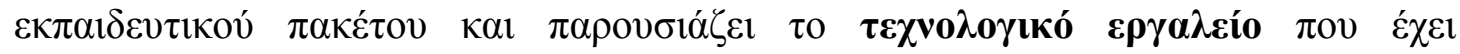

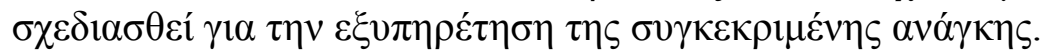

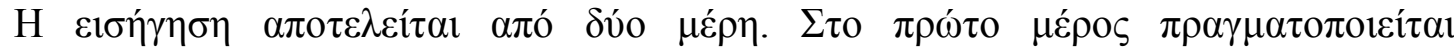

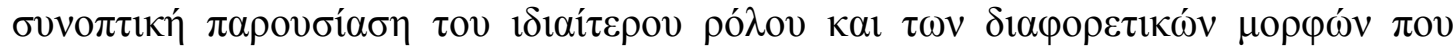

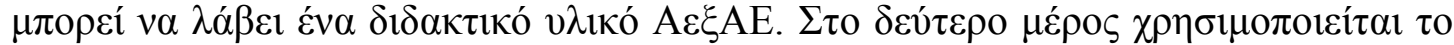

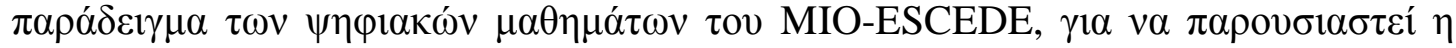

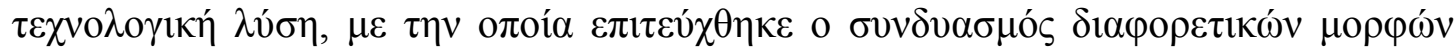

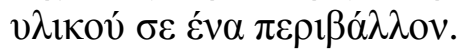

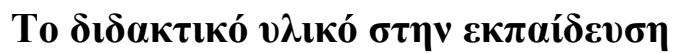

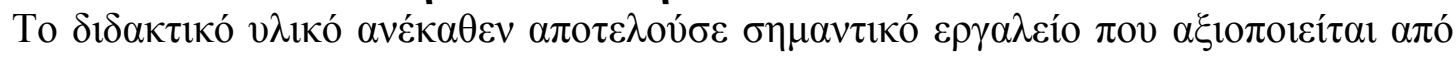

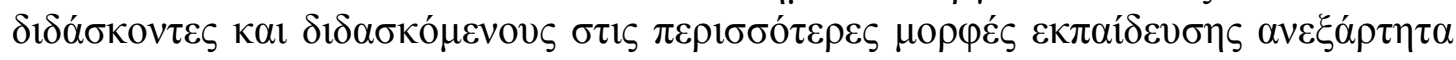

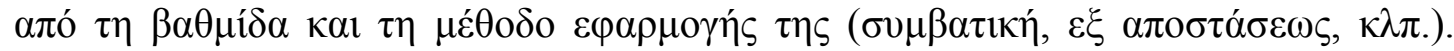

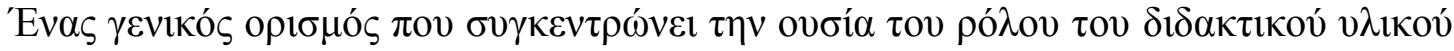




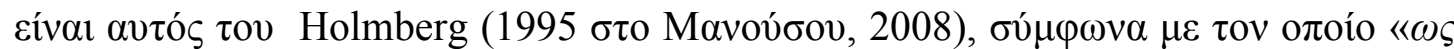

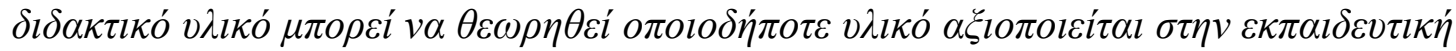

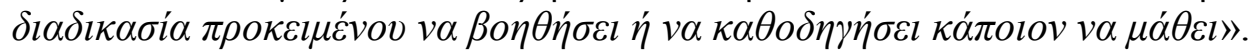

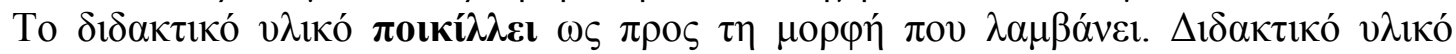

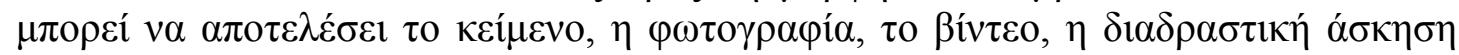

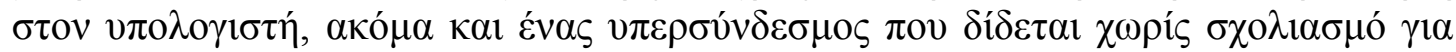

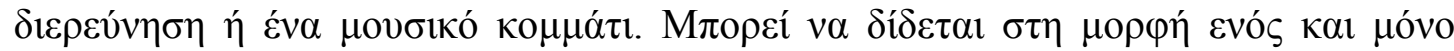

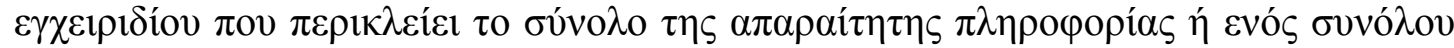

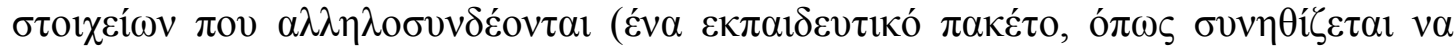

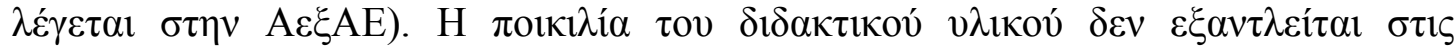

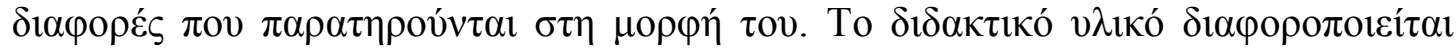

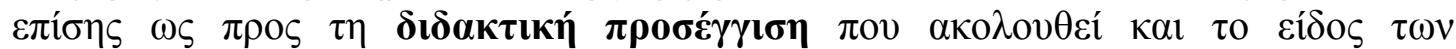

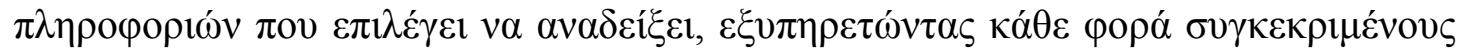

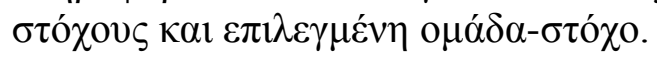

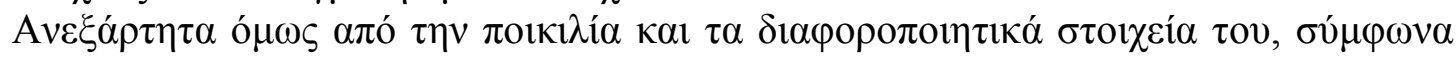

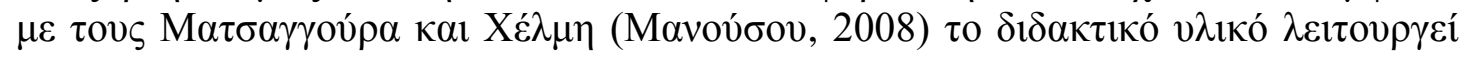

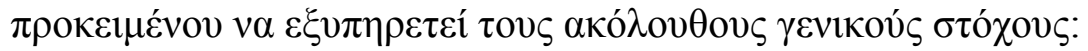

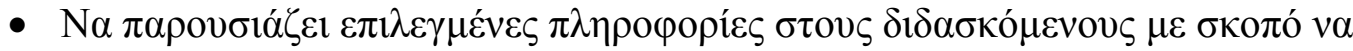

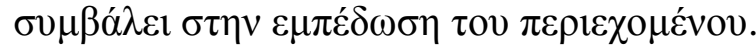

- $\mathrm{N \alpha} \kappa \alpha \tau \varepsilon v \theta u ́ v \varepsilon 1 ~ \tau \eta v ~ \varepsilon \kappa \pi \alpha \imath \delta \varepsilon v \tau \imath \kappa \eta ́ ~ \delta 1 \alpha \delta 1 \kappa \alpha \sigma i ́ \alpha$.

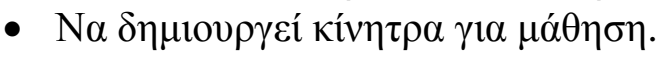

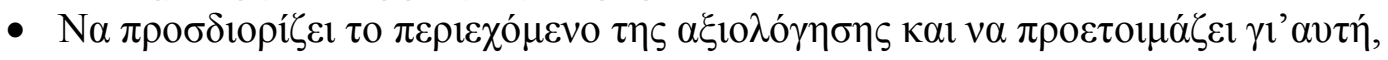
к.á.

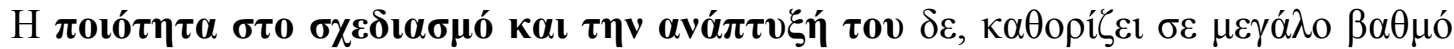

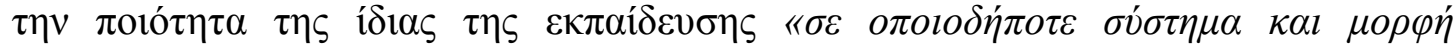

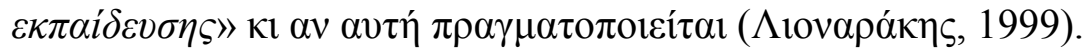

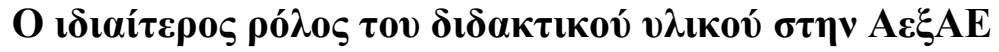

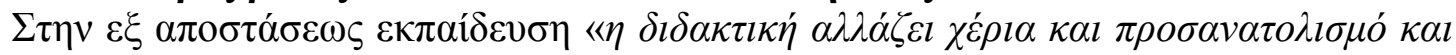

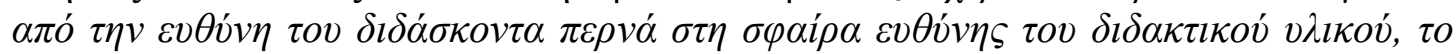

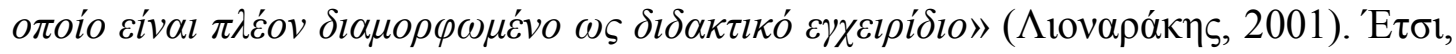

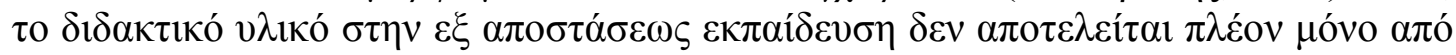

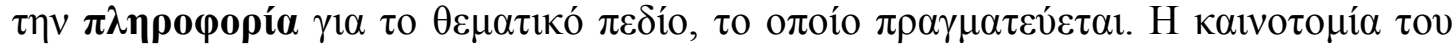

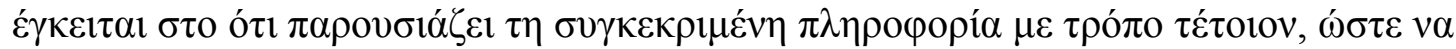

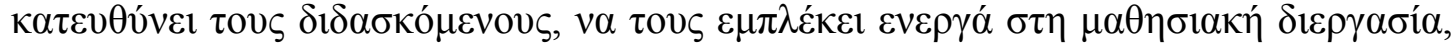

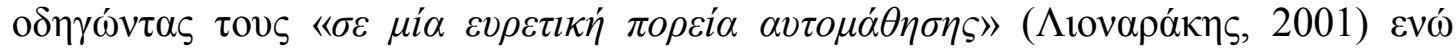

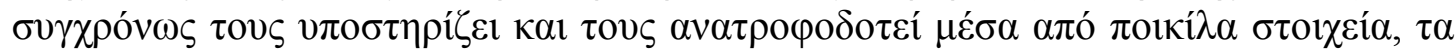

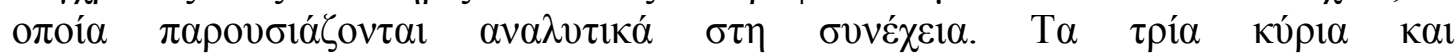

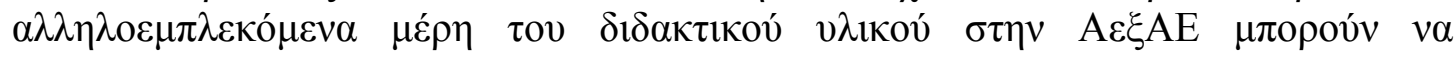
$\pi \alpha \rho \alpha \sigma \tau \alpha \theta$ ov́v $\omega \varsigma \varepsilon \xi \dot{\eta} \varsigma:$

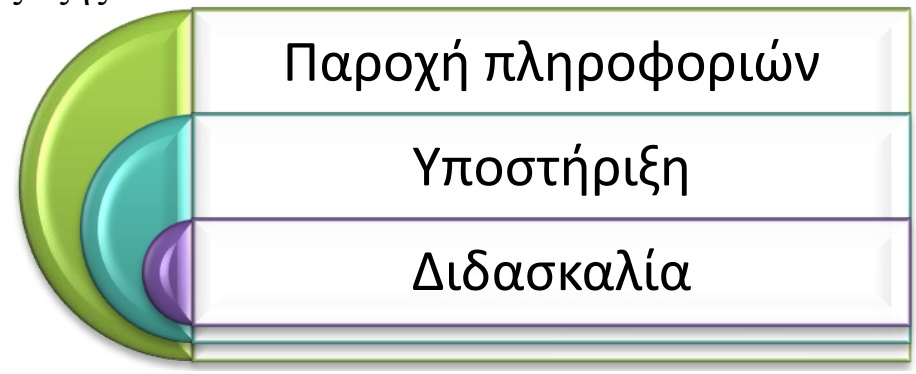

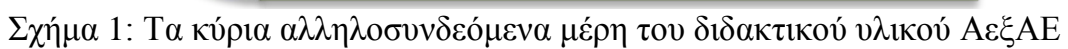




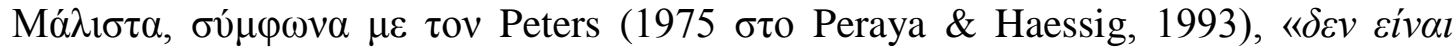

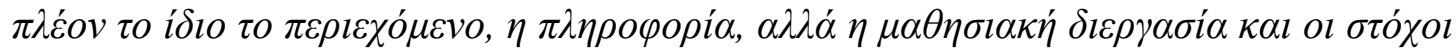

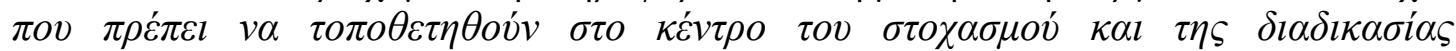

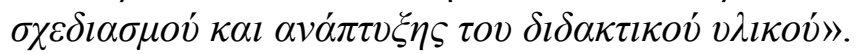

\section{Oı}

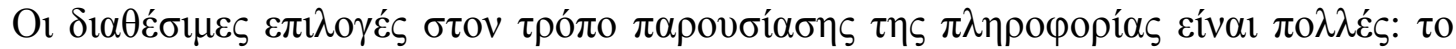

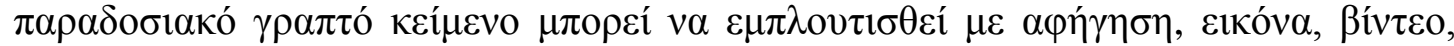

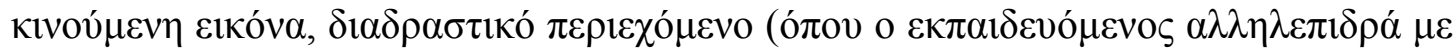

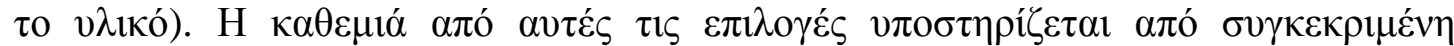

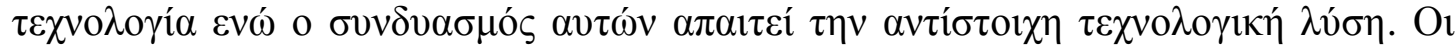

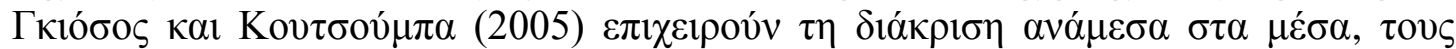

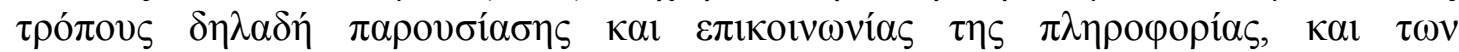

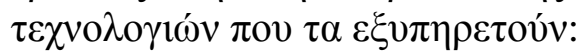

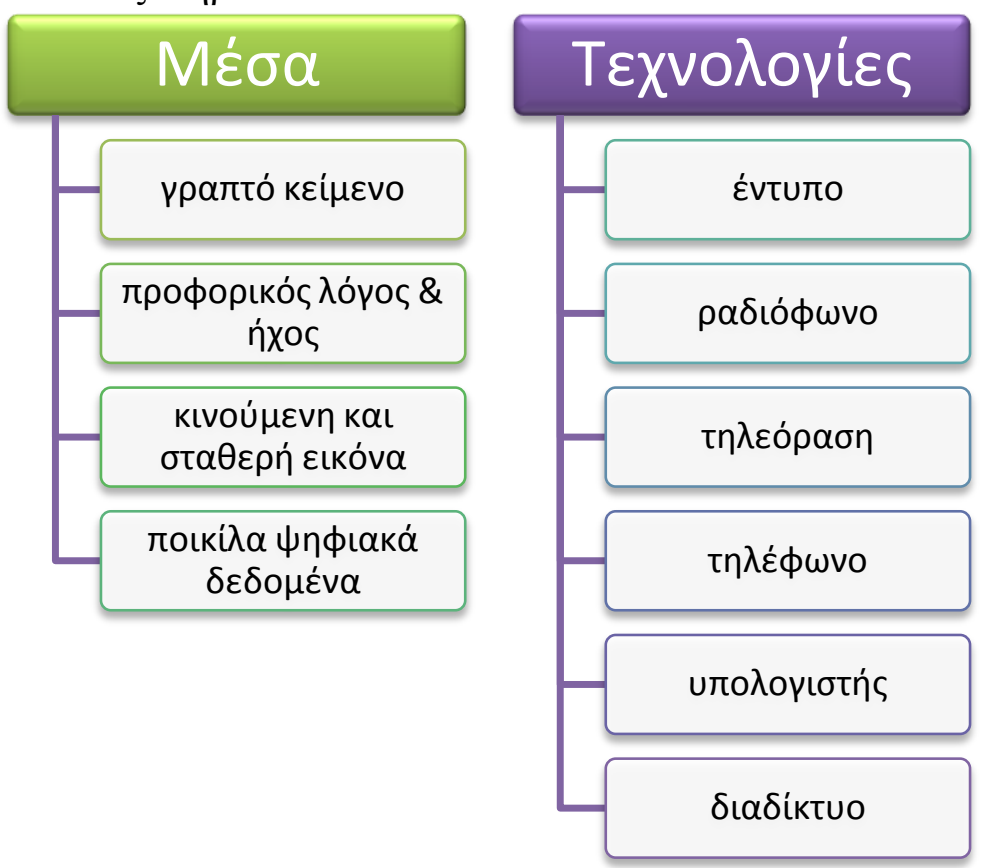

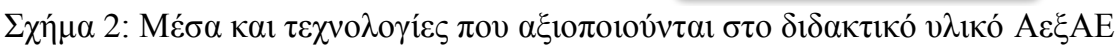

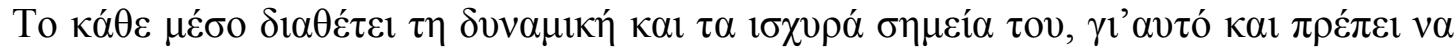

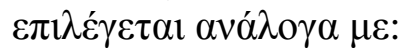

- $\tau i \varsigma \alpha v \alpha ́ \gamma \kappa \varepsilon \varsigma \tau о \mathrm{ov} \pi \varepsilon \rho 1 \varepsilon \chi 0 \mu \varepsilon ́ v o v$,

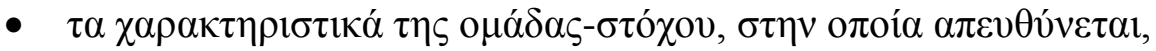

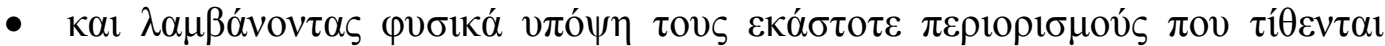

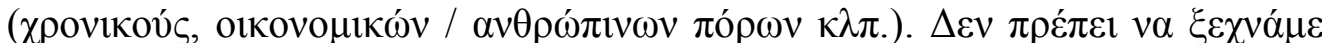

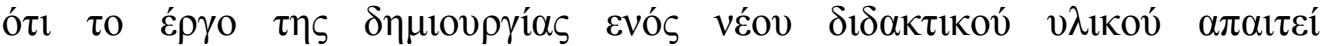

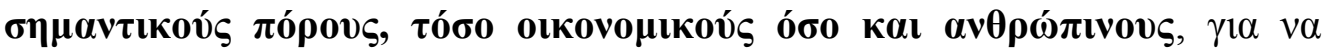

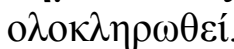

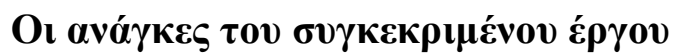

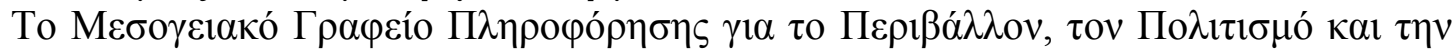

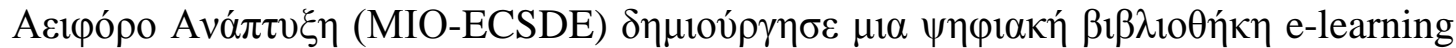

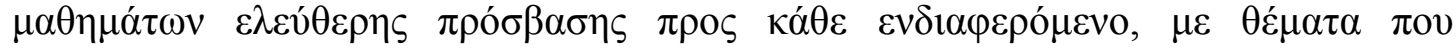

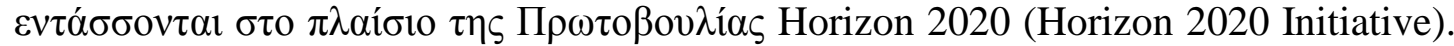

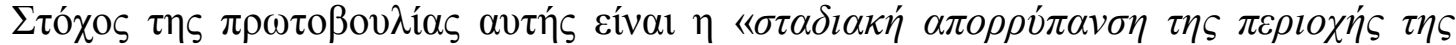

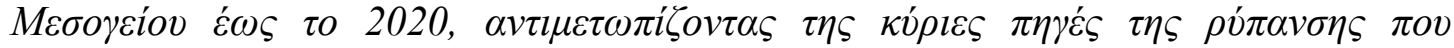




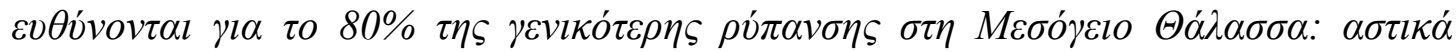

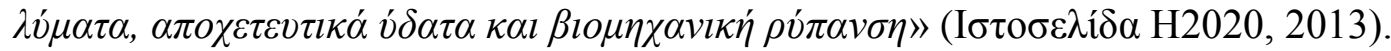

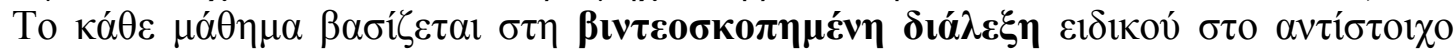

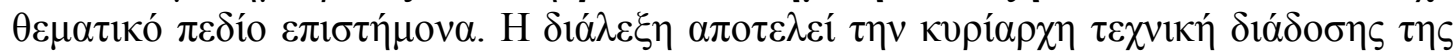

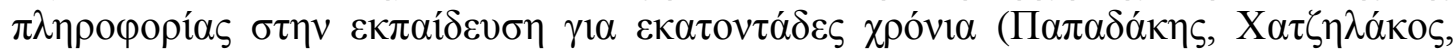

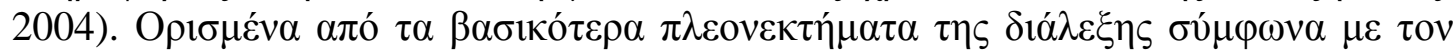

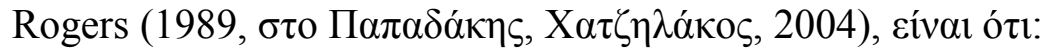

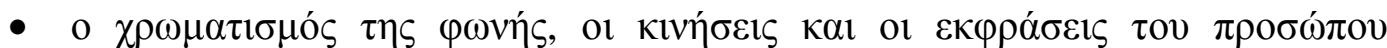

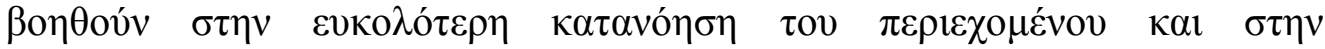

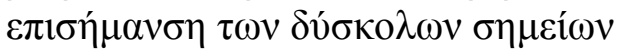

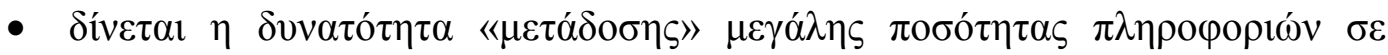

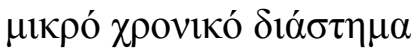

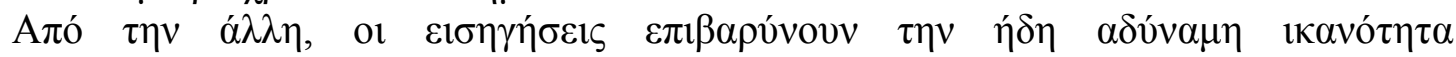

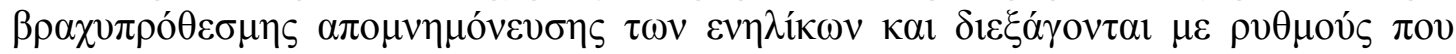

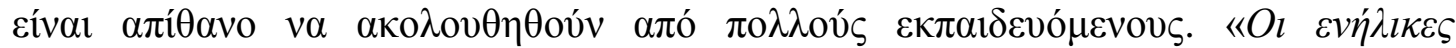

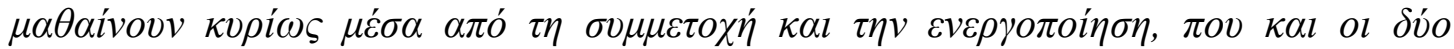

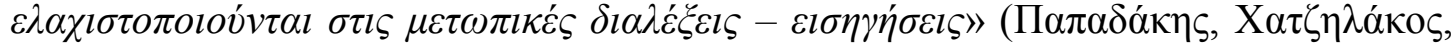
2004).

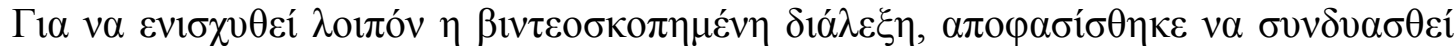

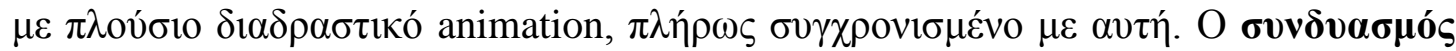

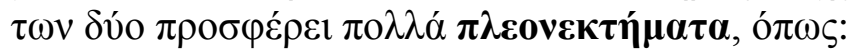

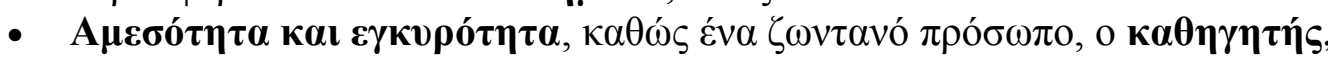

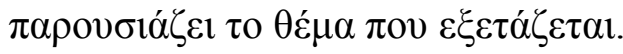

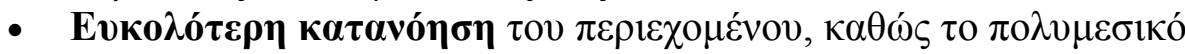

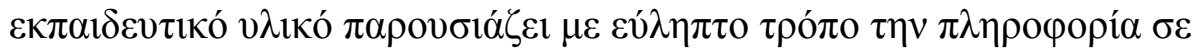

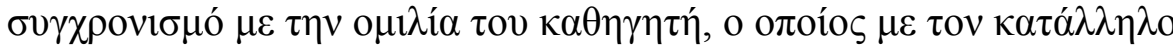

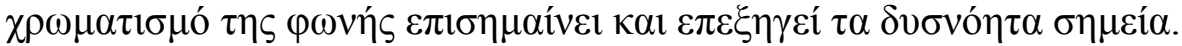

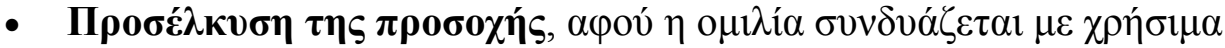

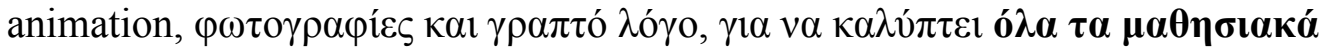
$\sigma \tau v \lambda$.

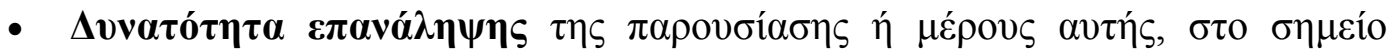

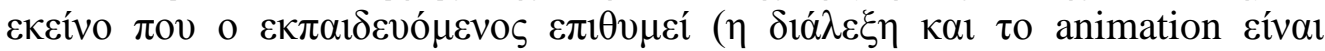
$\left.\pi \lambda \eta ́ \rho \omega \varsigma \sigma v \gamma \chi \rho \circ v^{\prime} \sigma \mu \varepsilon \dot{v} \alpha\right)$.

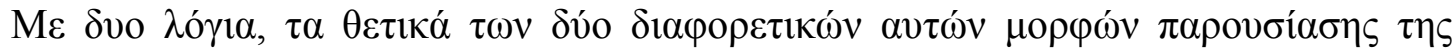

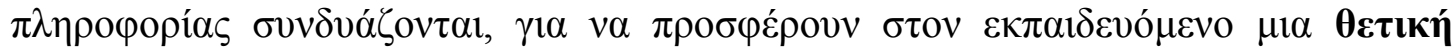

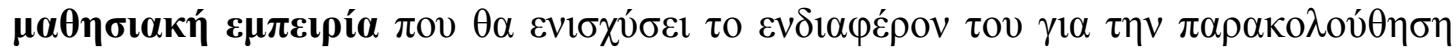

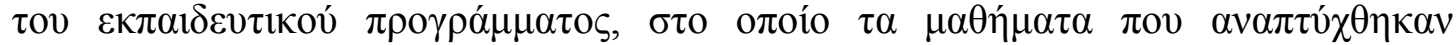
$\varepsilon v \tau \alpha ́ \sigma \sigma o v \tau \alpha$.

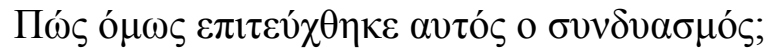

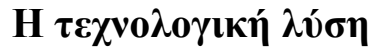

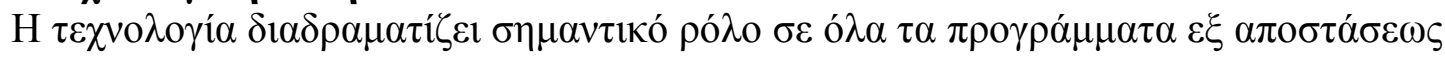

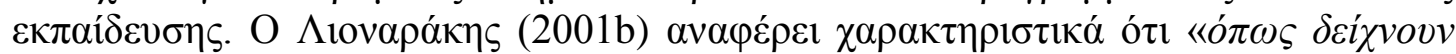

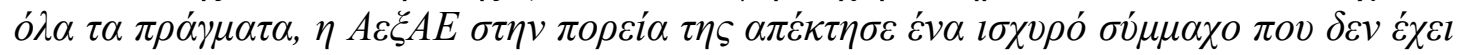

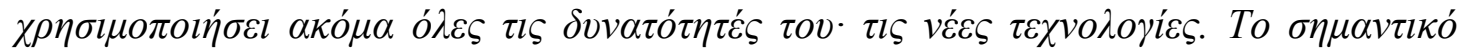

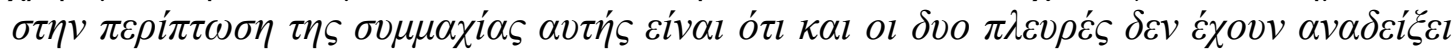

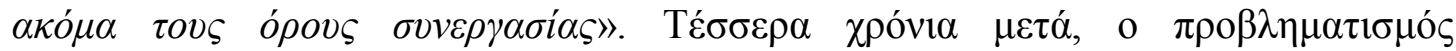
$\varepsilon \pi \varepsilon \kappa \tau \varepsilon i ́ v \varepsilon \tau \alpha \mathrm{l}:$

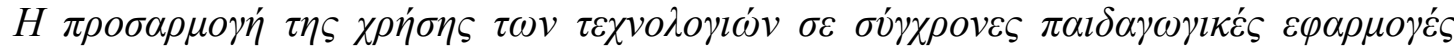

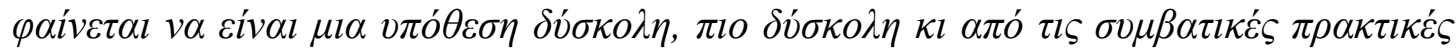




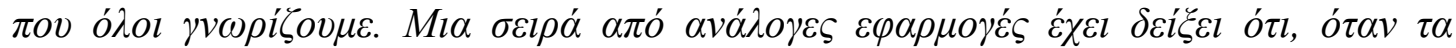

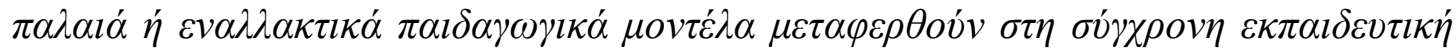

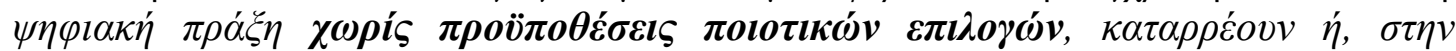

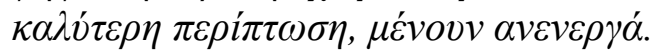

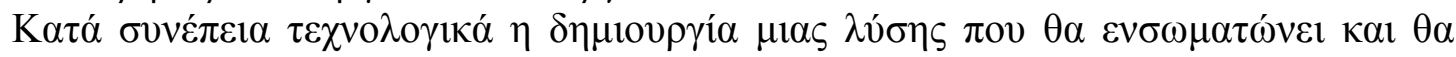

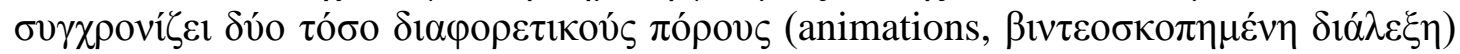

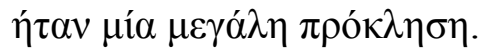

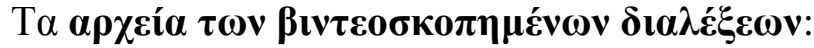

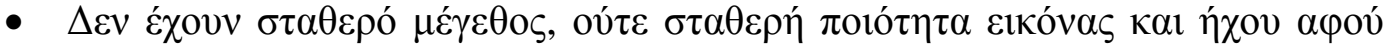

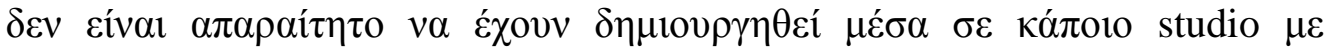

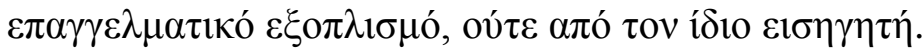

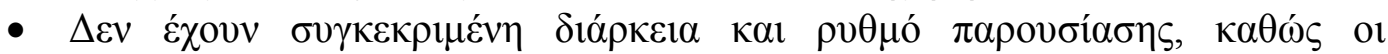

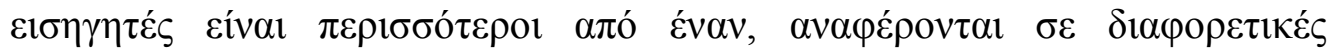

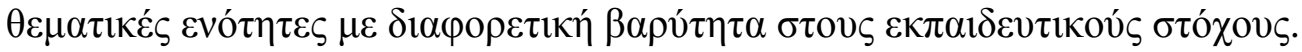

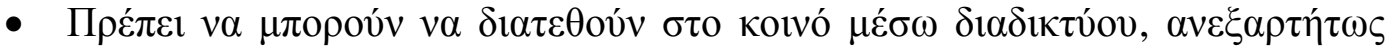

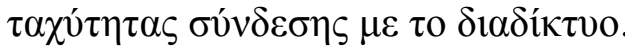

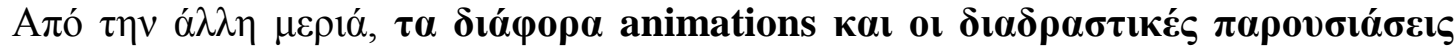
$\varepsilon \dot{\pi} \pi \varepsilon \pi \varepsilon$ :

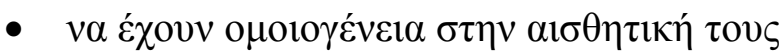

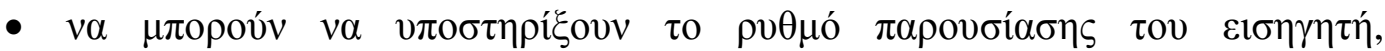

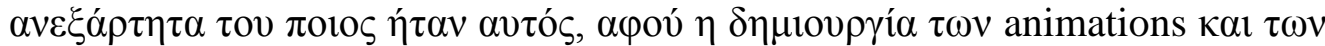

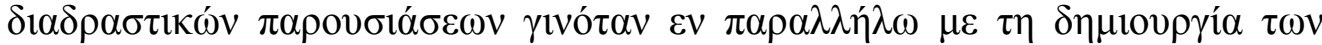

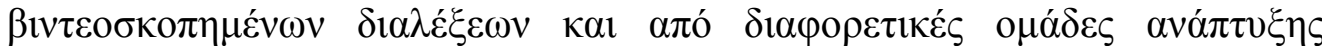

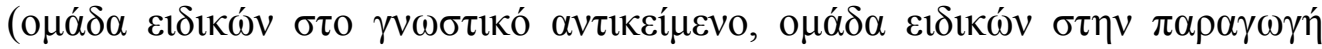

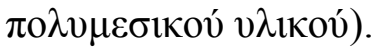

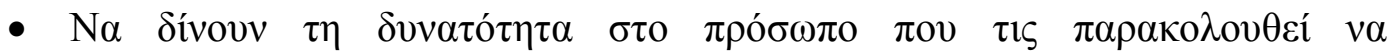

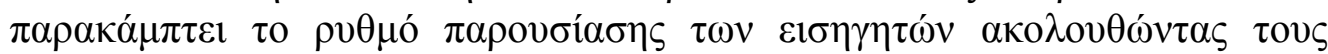

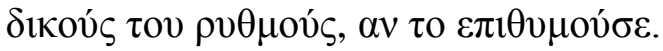

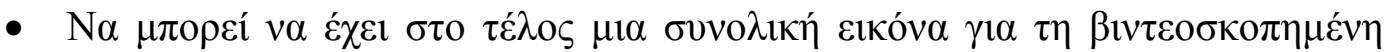

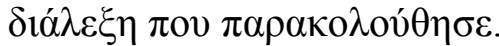

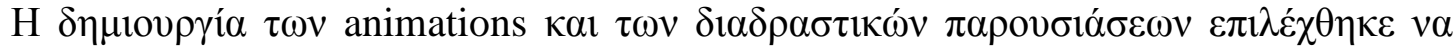

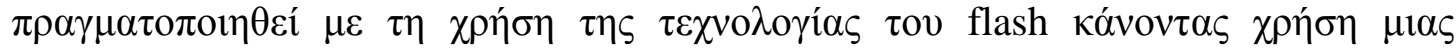

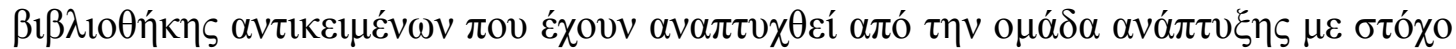

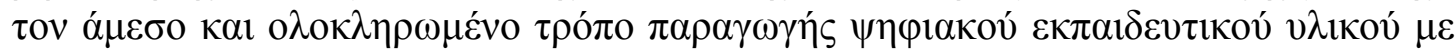

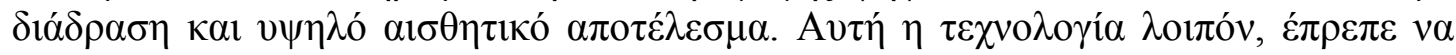

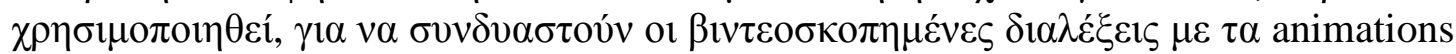

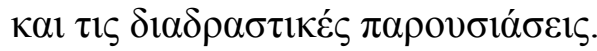

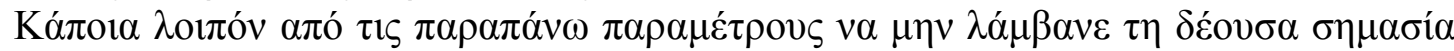

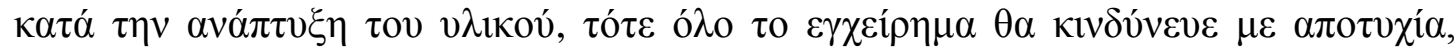

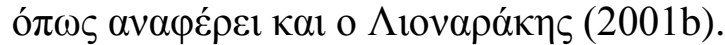

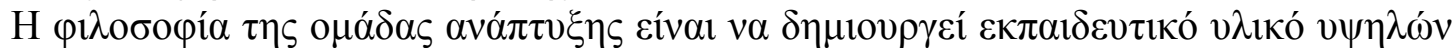

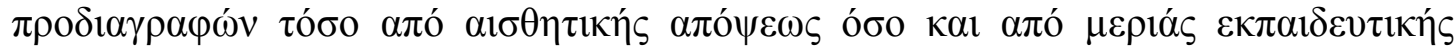
$\alpha \rho \tau ı o ́ \tau \eta \tau \alpha \varsigma$.

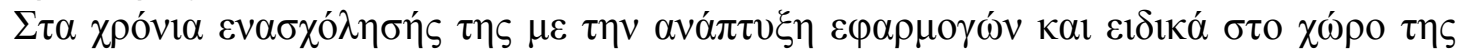

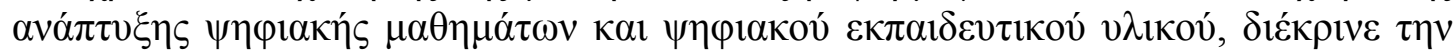

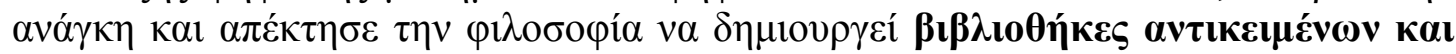

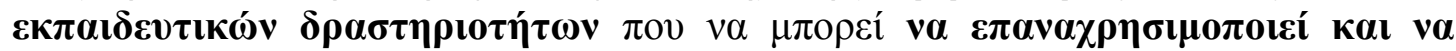

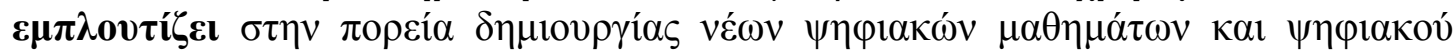

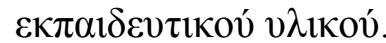




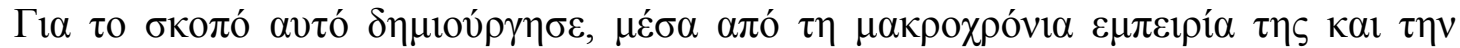

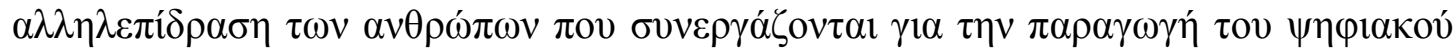

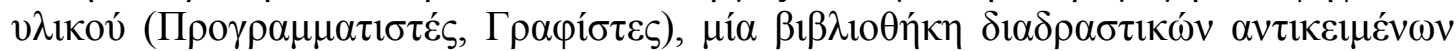

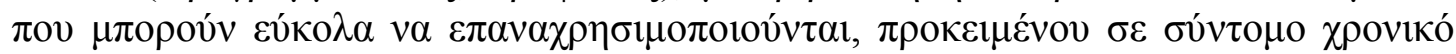

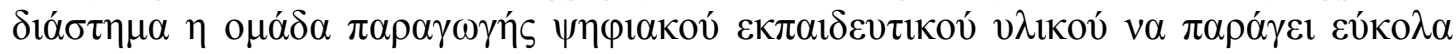

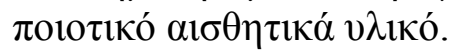

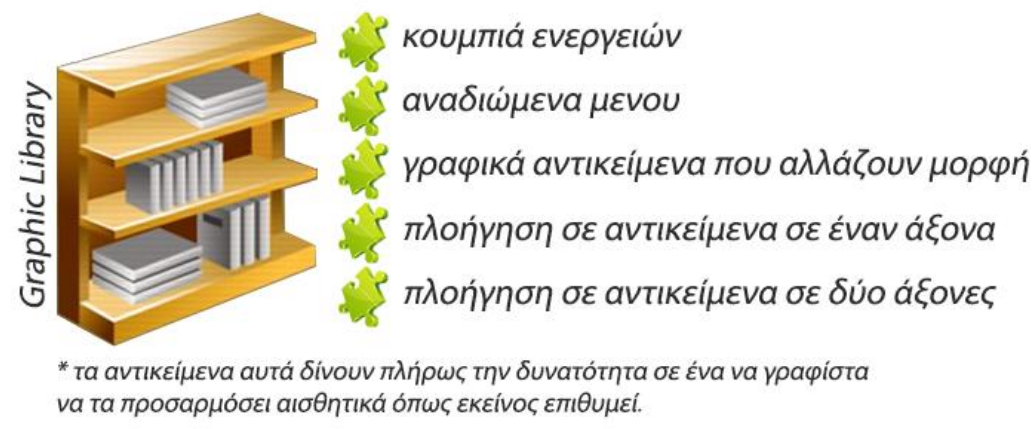

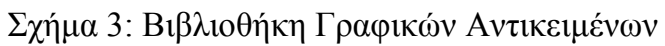

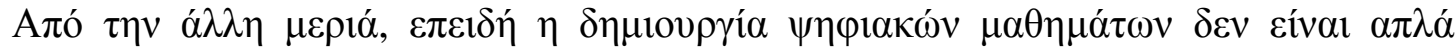

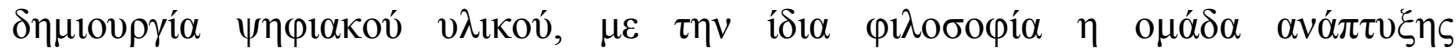

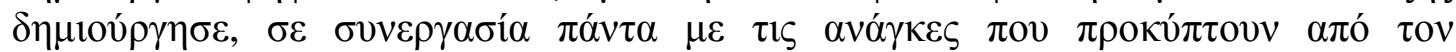

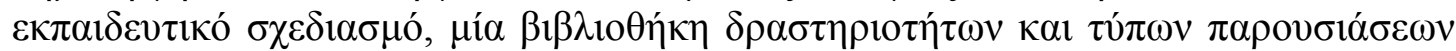

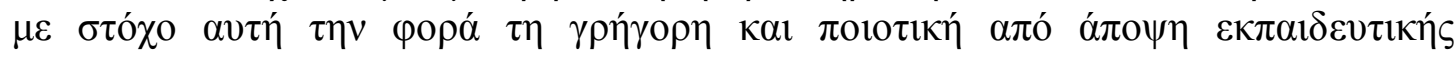

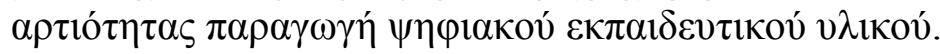

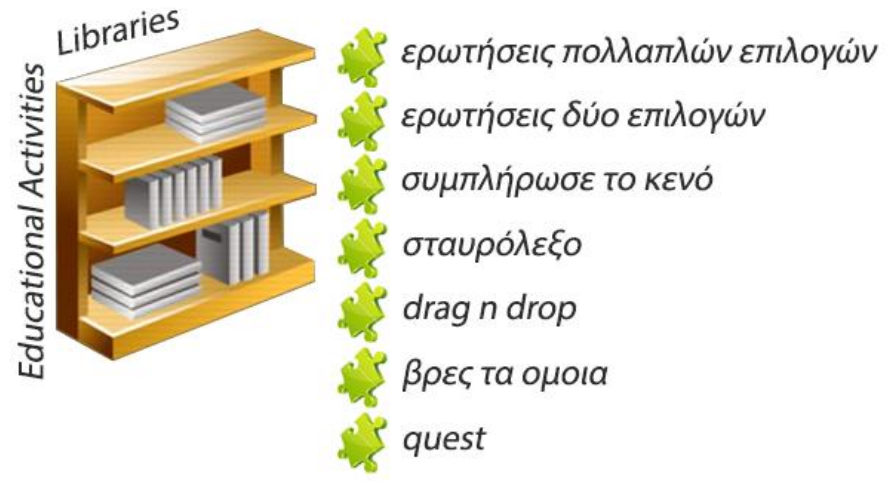

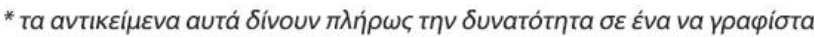

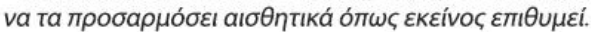

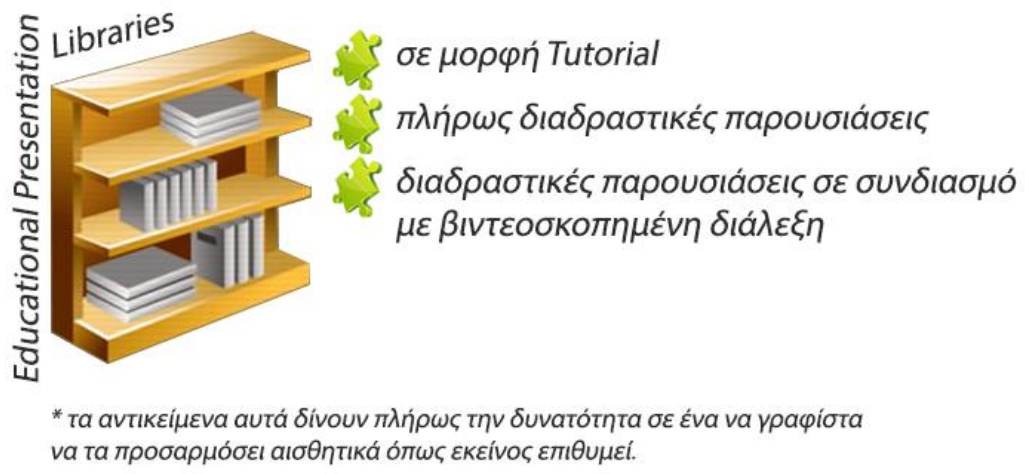

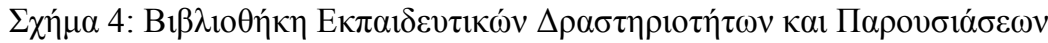




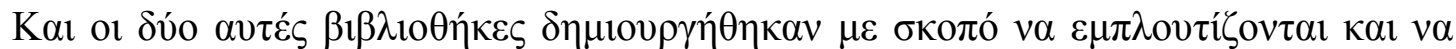

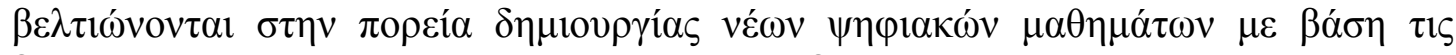

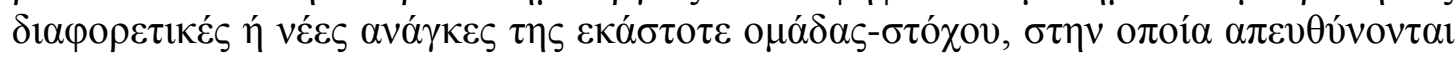

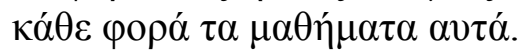

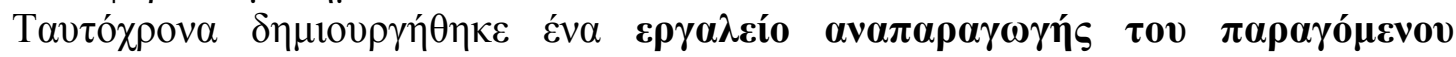

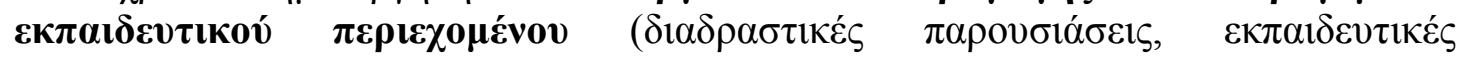

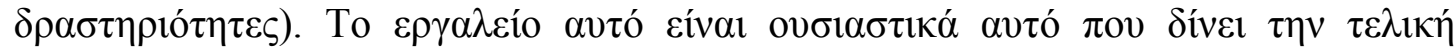

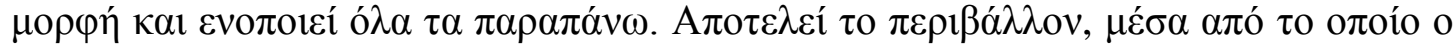

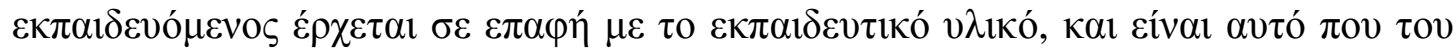

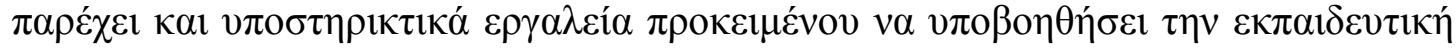

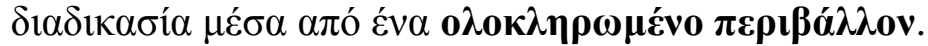

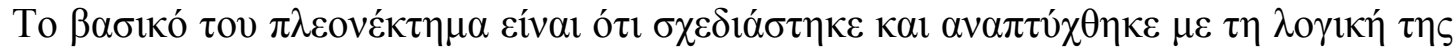

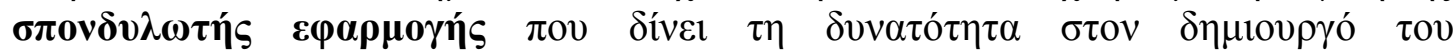

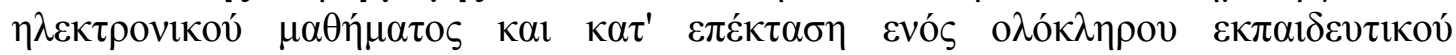

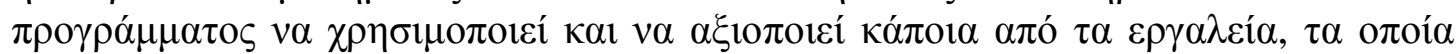

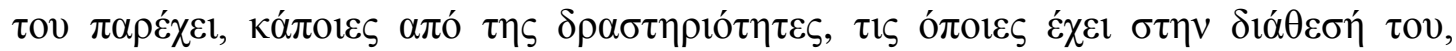

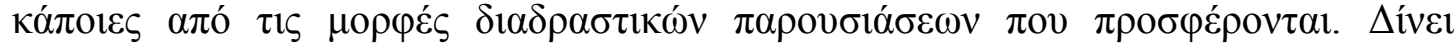

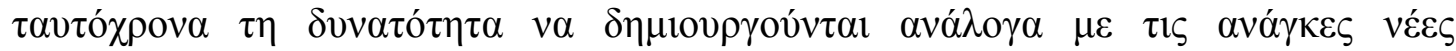

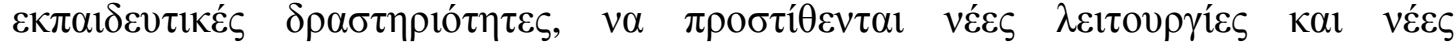
$\delta v v \alpha \tau o ́ \tau \eta \tau \varepsilon \varsigma$.

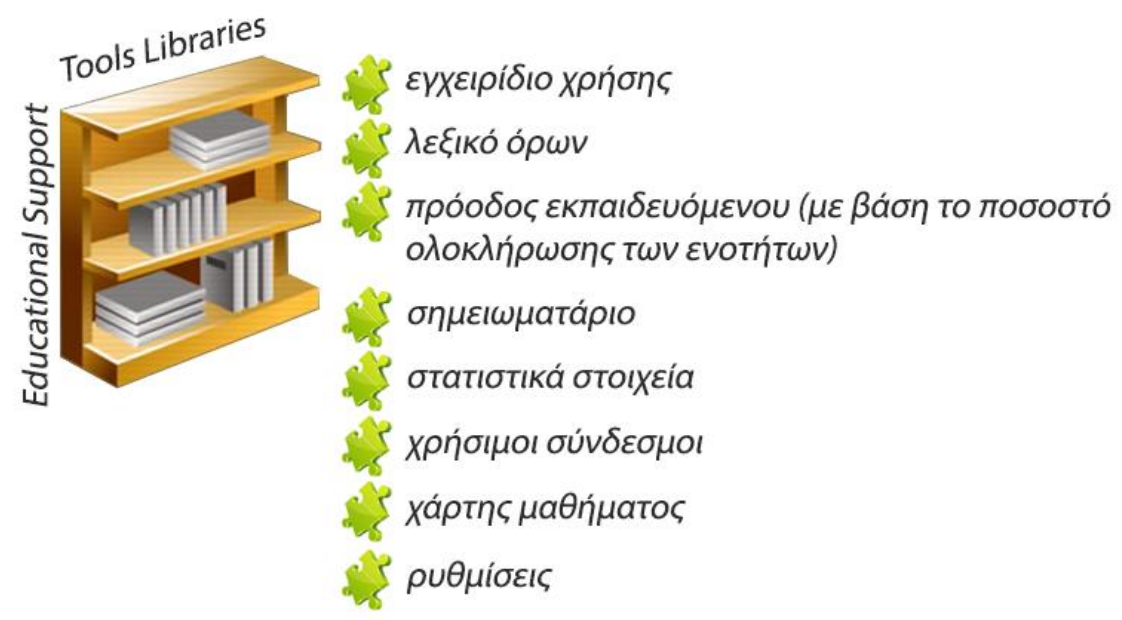

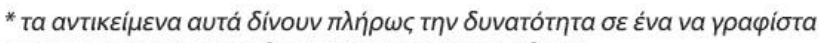

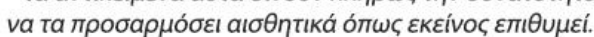

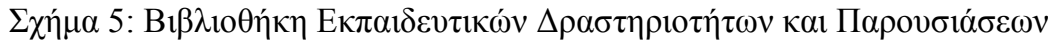

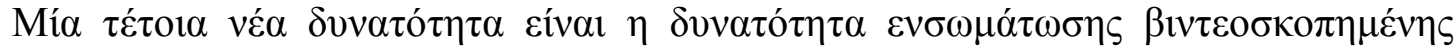

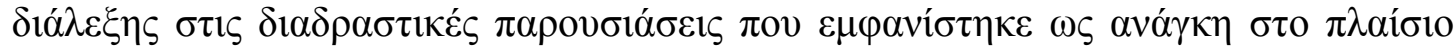

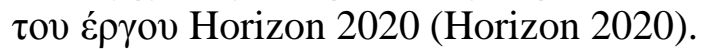




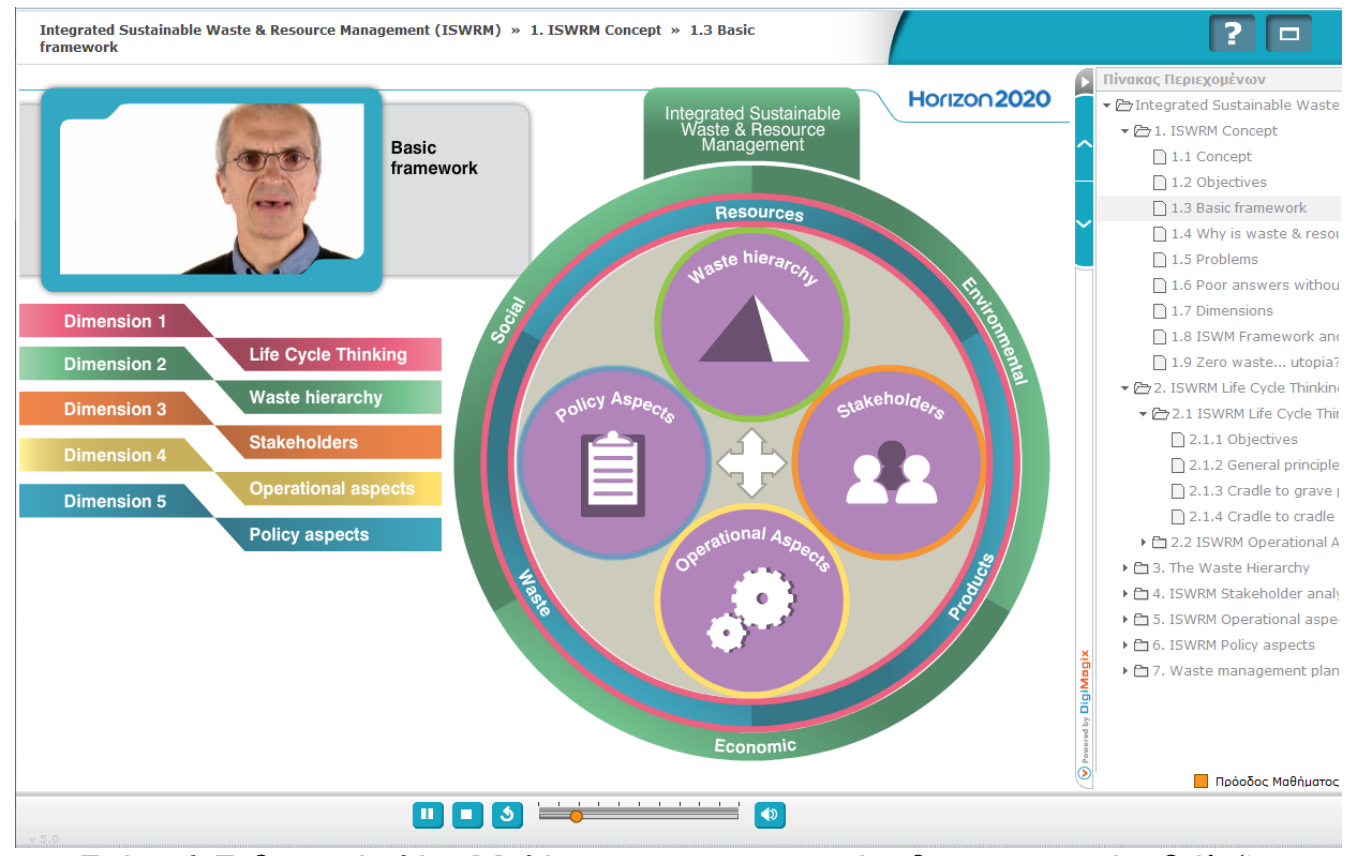

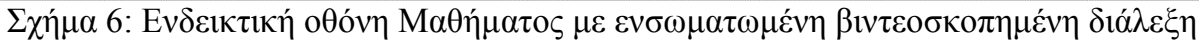

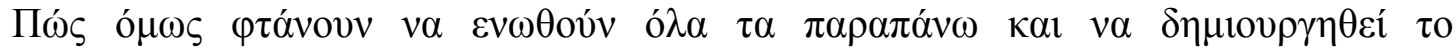

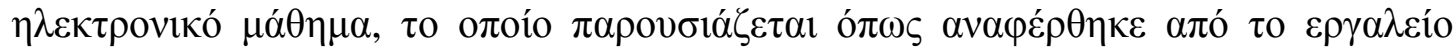

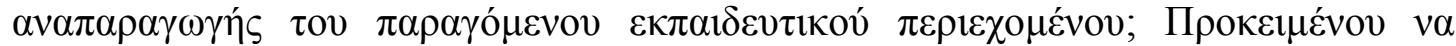

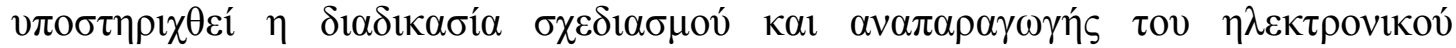

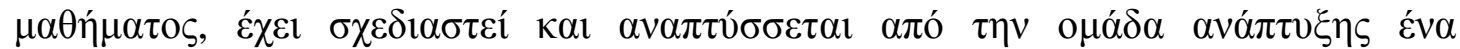

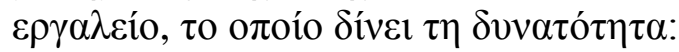

- $\quad$ $\quad \alpha \alpha \chi \varepsilon \delta 1 \alpha \sigma \tau \varepsilon i ́ \eta \eta$

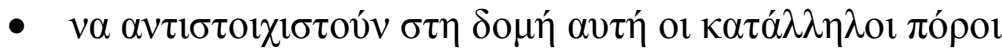

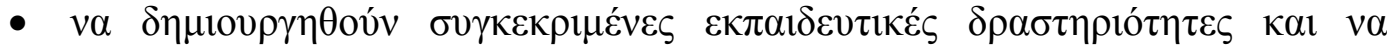

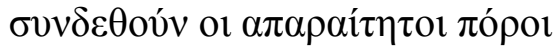

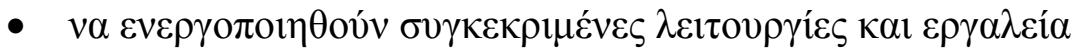

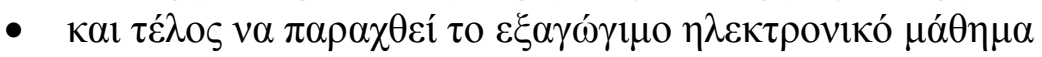

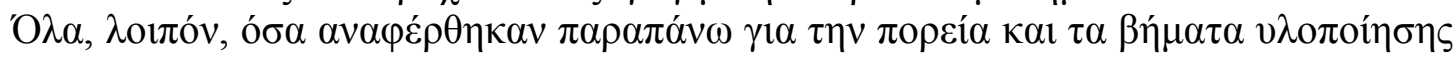

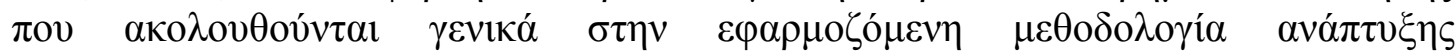

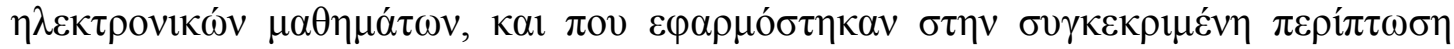

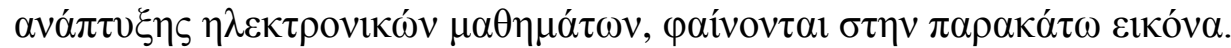




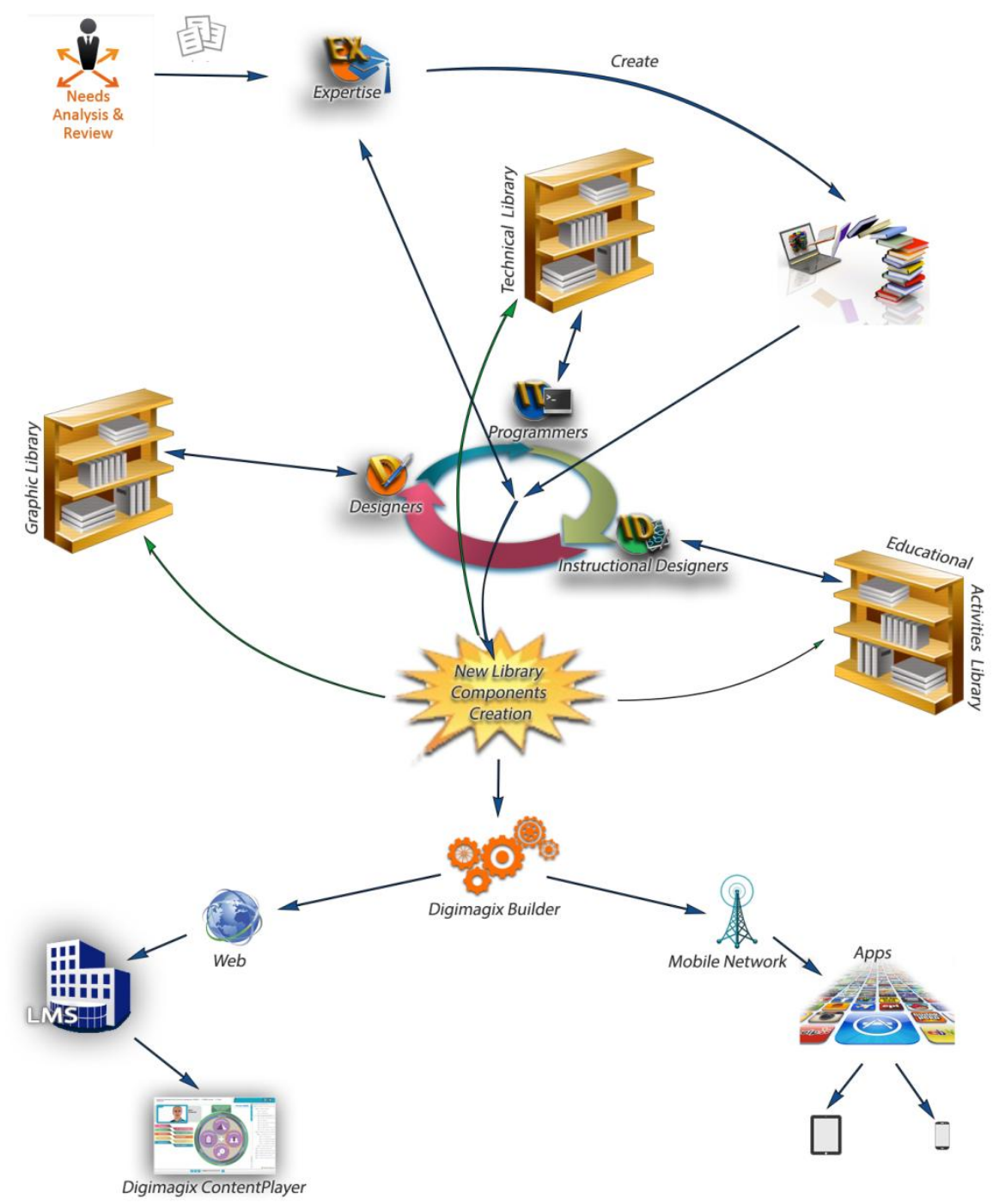

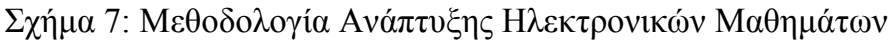

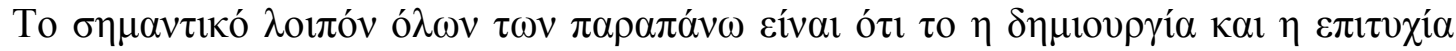

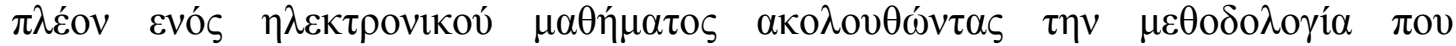

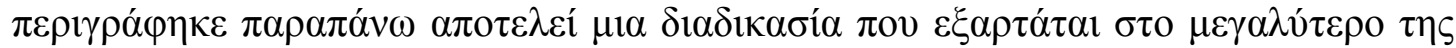

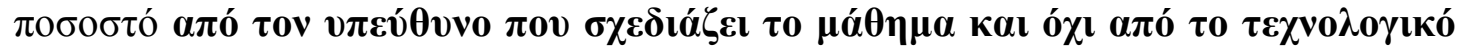

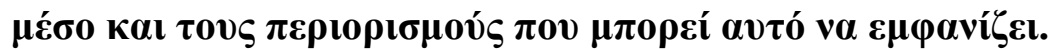

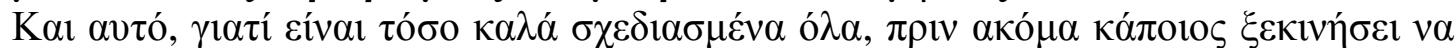

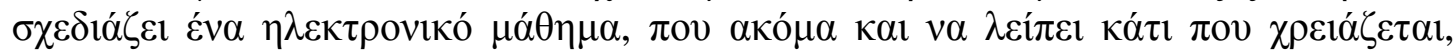

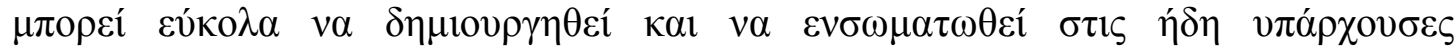
$\beta \imath \beta \lambda \imath \theta \dot{\kappa} \kappa \varepsilon \varsigma$.

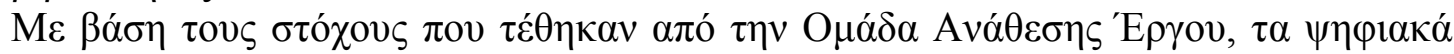

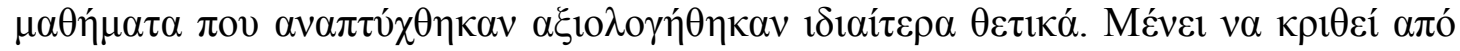

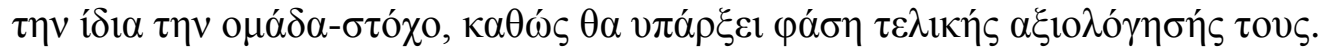

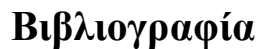

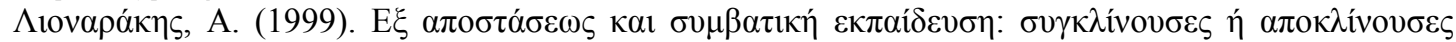

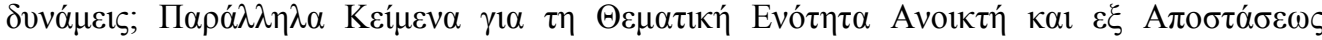

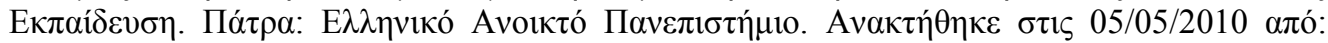
http://leandros.physics.uoi.gr/odl/input/art-lion1.htm

SECTION B: applications, experiences, good practices, descriptions and outlines, educational activities, issues for dialog and discussion 


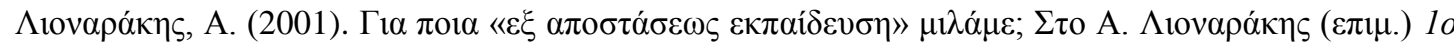

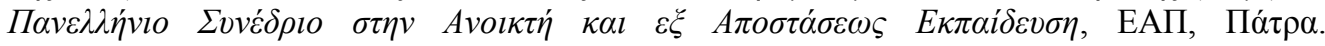

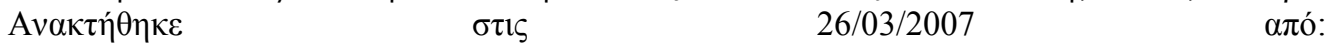
http://www.eap.gr/news/EXAGGELIA_SYNEDRIOU/synedrio/html/sect2/34.htm

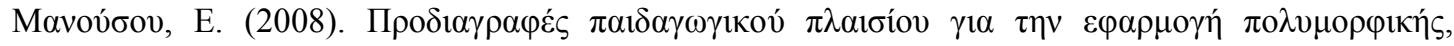

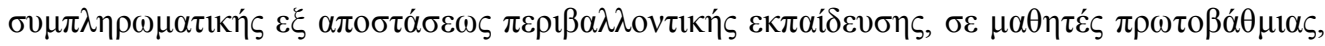

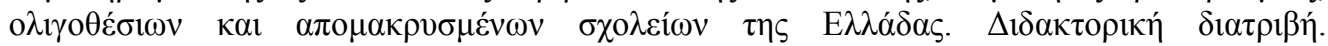

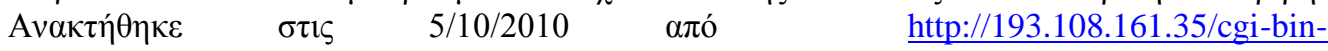
EL/egwcgi/167673/showfull.egw/1+0+1+full

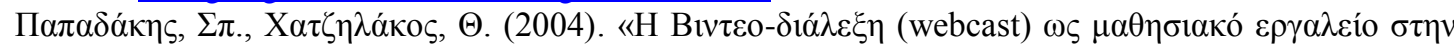

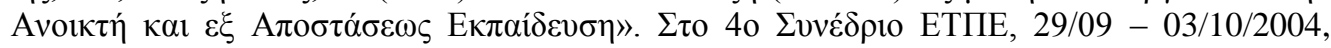
$\Pi \alpha \nu / \mu 10$ A $\theta \eta v \omega ́ v$.

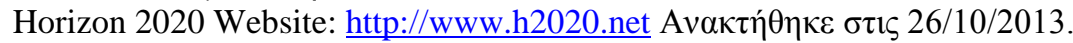

